\title{
Mechanical Characteristics of Two Environmentally Friendly Resins Reinforced with Flax Fibers
}

\author{
Dario Croccolo* - Massimiliano De Agostinis - Stefano Fini - Alfredo Liverani - \\ Nicolò Marinelli - Eugenio Nisini - Giorgio Olmi \\ University of Bologna, Department of Industrial Engineering, Italy
}

In this paper, a comparison between the mechanical characteristics of two different natural fiber composites has been carried out. The two composites were made using two different environmentally friendly resins, but with the same flax fiber reinforcement. Thirty-two specimens were tested for tension, bending and shear. The results obtained in the tensile and bending tests are acceptable according to the Standards, whereas those of the shear tests were discarded, since the samples exhibited unacceptable failure modes. In light of the results obtained, both in terms of strength and stiffness, the isophthalic resin (181EN2X) outperformed the vinyl ester resin (VEef220ST). In the case of the isophthalic resin, microscopic observations showed a good adhesion between the matrix and the fiber, with a small amount of air inclusions. The present study demonstrates that the mechanical characteristics of flax reinforced and environmentally friendly resins are similar to those achievable with the same fibers using conventional resins.

Keywords: natural fibre composites, mechanical properties, flax, environmentally friendly resin

Highlights

- Two different natural fiber composites have been compared.

- The two resins have wide applications in the marine industry.

- $\quad$ The two composites have been obtained with two different environmentally friendly resins.

- $\quad$ The mechanical properties of the manufactured composites have been determined.

- $\quad$ The mechanical properties of the Resin 181EN2X are significantly improved by the presence of the fiber reinforcement.

\section{O INTRODUCTION}

Over the past twenty years, polymer matrix composites reinforced with vegetable fibers have attracted great interest [1] and [2]. The increasing attention on these materials arises from both the excellent mechanical properties of vegetable fibers, such as high tensile strength for low density, low environmental impact, renewability, recyclability and low cost. Despite the good qualities of some types of vegetable fibers, such as flax, hemp and jute, vegetable fiber reinforced plastics are still mainly used for non-structural applications only. This is due to the low strength properties that can be achieved for the composite, despite its generally good impact resistance and low density. The mechanical response of a composite is strictly related to its structure [3] to [7]. The relatively poor mechanical properties of the vegetal fiber reinforced composites are usually due to the following: i) damage to the plant fibers during the extraction process, ii) variability of fiber characteristics depending on the source. Other drawbacks are the difficulty in finding fabrics specially made for composites, resulting in non-optimal orientation and volume fractioning of the fibers that can be obtained, and a poor affinity between the fiber and the matrix. Moreover, due to the short length of technical plant fibers, the reinforcement needs to be in the form of staple fiber yarns, which have a twisted structure. Although twisting facilitates yarn processing, it has several detrimental effects on the composites produced [8]. Natural fibers also have limited thermal stability and harsh environments may seriously affect their mechanical properties. There is, finally, a major drawback related to the application of natural fibers for the reinforcement of polymeric matrices: natural fibers exhibit high moisture absorption [9] due to the presence of hydroxyl and other polar groups in their constituents. In the present study, the mechanical characteristics of composites obtained using environmentally friendly polymer matrices, reinforced with flax fibers derived from the textile industry, were evaluated. The aim of the research is to assess the potential of low cost vegetable fiber reinforced plastics. A set of experiments was carried out in order to show whether the combination of flax fiber reinforcement and environmentally friendly resins could lead to high-performance materials, with comparable structural properties to other composites made using natural fibers and non-environmentally friendly polymer matrices. 


\section{STATE OF THE ART: VEGETABLE FIBERS AND RESINS}

\subsection{Vegetable Fibers}

There are six basic types of natural fibers. They are classified as follows: bast fibers (jute, flax, hemp, ramie and kenaf), leaf fibers (abaca, sisal and pineapple), seed fibers (coir, cotton and kapok), core fibers (kenaf, hemp and jute), grass and reed fibers (wheat, corn and rice) and all other types (wood and roots) [10]. The best fibers are bast fibers and they are extracted from the stems of plants such as flax, jute and hemp. These fibers are composed of clusters made up of long elementary fibers. The elementary fibers have varying lengths depending on the kind of plant, ranging from $20 \mathrm{~mm}$ to $70 \mathrm{~mm}$ for flax against $2 \mathrm{~mm}$ to $3 \mathrm{~mm}$ for softwood. They have extremely thin cell walls $(5 \mu \mathrm{m}$ up to $15 \mu \mathrm{m})$ and a diameter between $15 \mu \mathrm{m}$ and $35 \mu \mathrm{m}$ [11]. These clusters of elementary fibers, whose cross section consists of 12 to 48 cells, are called technical fibers. Technical fibers are the basic element for both the textile industry and the preparation of composites. For example, flax technical fibers have lengths in the range $0.3 \mathrm{~m}$ to $0.6 \mathrm{~m}$ and diameters falling between $50 \mu \mathrm{m}$ and $500 \mu \mathrm{m}$. As shown in Fig. 1, inside each technical fiber, the elementary fibers are joined together by a matrix (middle lamella) primarily consisting of pectin and hemicellulose (structures composed of low molecular weight polysaccharides). Typically, elementary fibers display a 5- to 7-edge polyhedral section, which improves the packaging capability with respect to a circular section. They consist mainly of cellulose, lignin and non-structural compounds such as waxes, salts and organic nitrogen compounds [11]. The structural characteristics of elementary fibers are mainly due to cellulose, which has a high molecular weight and a Young's modulus of E = $135 \mathrm{GPa}$ [13].

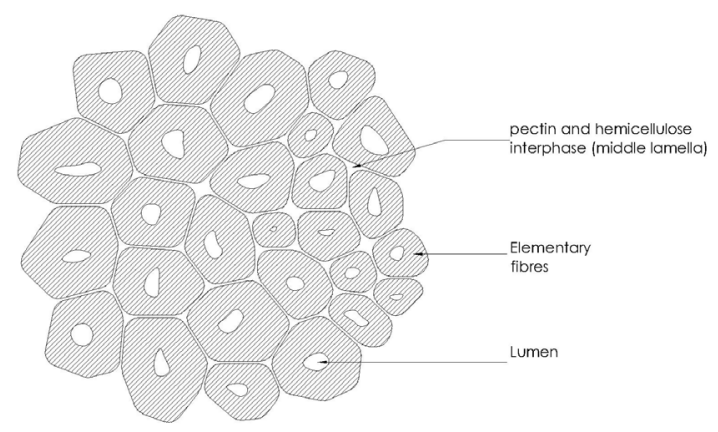

Fig. 1. Cross section of a technical fiber (bundle of elementary fibers)
Inside the cell wall, cellulose can be mainly found in the form of bundles of cellulose polymers, joined together by means of polysaccharides (hemicellulose) and lignin. The elementary fibers have an organized structure of multiple layers, with a very thin outer skin (the primary cell wall, for flax it is about $2 \mu \mathrm{m}$ thick) and an intermediate zone (secondary cell wall), which is the main bearing element split into four parts. These are named S1 to S3, along with a hollow central part called the lumen (Fig. 2). The so-called S2 part is the most important in terms of volume amount, as it occupies about $80 \%$ of the fiber volume. The secondary cell wall consists of cellulose microfibers spiral-wound with a certain tilt angle with respect to the elementary fiber axis. The secondary cell wall is included in a matrix of hemicellulose and lignin. In the S1 and S3 areas, microfibers are wound with both right hand and left hand helixes, hence forming a lattice structure. Conversely, in the S2 area, they are wound in one direction only and with a reduced helix angle in comparison with other areas. Referring to the S2 area, fibers derived from wood exhibit values for the tilt angle between $10^{\circ}$ and $30^{\circ}$, whereas bast fibers have values lower than $10^{\circ}$, sometimes dropping down to as low as $2^{\circ}$.

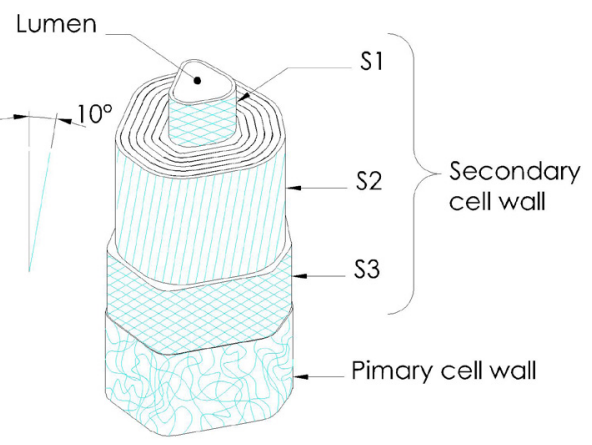

Fig. 2. Structure of a bast elementary fiber

It has been found that the mechanical properties of the fibers are related to the tilt angle in the S2 area. Small values of the tilt angle are generally associated with high values of tensile strength and of the elastic modulus of the elementary fiber. Therefore, the architecture of the $\mathrm{S} 2$ area is responsible for the tensile strength and the stiffness of the elementary fiber, the $\mathrm{S} 1$ area enhances the stability of the fiber against the compressive loads, whereas the $\mathrm{S} 3$ area reacts to the internal pressure of the cell [14]. The density of the cell wall is about $1500 \mathrm{~kg} \cdot \mathrm{m}^{-3}$ and appears to be almost independent of the plant species the fiber is extracted from. Conversely, the density of different plant fibers is mainly influenced by the extension of 
the hollow central area (lumen) and, consequently, by the plant age. For instance, for fibers extracted from a mature plant, the lumen area is less than $10 \%$ of the whole section of the fiber itself. Therefore, the average density of elementary fibers is quite low, on the order of $1350 \mathrm{~kg} \cdot \mathrm{m}^{-3}$. As for the mechanical properties of the technical fibers, significant discrepancies can be found between the values reported by different authors [11] and [15] to [17]. This occurrence is due to one or more of the following reasons [18]: (a) cultivation of the fiber, growth conditions of the plant, position of the fiber in the plant, maturity of the fiber and collection technique; (b) machining and extraction technique or mechanical modification of the fiber [8]; (c) testing methodologies and measurements performed according to different standards, and different environmental conditions during the tests. Table 1 summarizes the main physical and mechanical properties found in the literature [18] to [20] for some natural fibers. The large scattering in the tensile strength values may depend on the clamping length. In fact, for clamping lengths greater than $25 \mathrm{~mm}$, values of tensile strength of approximately UTS $=500$ $\mathrm{MPa}$ can be found, whereas for lower clamping lengths (lower than $3 \mathrm{~mm}$ ) the tensile strength may increase up to $U T S=800 \mathrm{MPa}$ to $1000 \mathrm{MPa}$. Such behavior is due to the transition from a cohesive failure of the interface made of pectin adhesive, which joins the elementary fibers together, to the rupture of the elementary fibers themselves. Moreover, when the clamping length increases, more defects are found in the specimen [16].

\subsection{Resins}

The resins that are used in fibre-reinforced composites are composed of long chain-like molecules consisting of many simple repeating units. Resins can be classified under two types, 'thermoplastic' and 'thermosetting', according to the effect of heat on their properties. Thermoplastics are softened by heating and harden again after cooling. Widely used thermoplastics include nylon, polypropylene and ABS, which can be reinforced, usually by short, chopped fibres, such as glass. Thermosetting materials, or 'thermosets', are formed from an in situ chemical reaction, where the resin and hardener or the resin and catalyst are mixed together and undergo a nonreversible chemical reaction to form a hard, infusible product. Once cured, thermosets do not become liquid again if heated, although their mechanical properties experience a significant change above a certain temperature. This temperature is known as the glass transition temperature $(T g)$ and depends on the particular resin system used, on its degree of cure and on whether it was mixed correctly. Although there are many different types of thermosetting resins being used in the composite industry, the structural parts are mainly made of polyester, vinylester and epoxy. Most polyester resins are of the 'unsaturated' type. Unsaturated polyester resin is a thermoset, capable of being cured from a liquid or solid state under suitable conditions. Orthophthalic and isophthalic are the main types of polyester resins. The orthophthalic polyester resin is the most conventional and economical. The isophthalic resin is now becoming the preferred material in marine industries, due to its higher water resistance. The addition of styrene enables the resin to cure from a liquid to a solid by 'cross-linking' the molecular chains of the polyester. These resins can therefore be moulded without the use of pressure and are called 'contact' or 'low pressure' resins. Vinylester resins have a similar molecular structure, but different locations of their reactive sites, posed only at the ends of the molecular chains. An important issue is related to the molecular chain being able to absorb shock loads over its whole length. As a consequence, vinylester resins are made tougher and more resilient than polyesters. The vinylester molecule also features fewer ester groups. These ester groups commonly have a detrimental effect, as they suffer water degradation by hydrolysis. Therefore, a further important feature of vinylesters is their better resistance to water and many other chemicals than their polyester counterparts. Therefore, they are widely used in applications involving liquids, such as pipelines and chemical storage tanks. Epoxy resins are the resins exhibiting the best mechanical properties and a good resistance to environmental degradation, with many applications in aircraft construction. When used as laminating resins, their enhanced adhesive properties and resistance to water degradation, make them suitable to many applications in the marine industry.

\section{MATERIALS AND METHODS}

As mentioned in the introduction, the present study focuses on flax reinforced composites. In fact, flax is characterized by good mechanical and physical properties, such as tensile strength, elastic modulus, and density (Table 1), moreover its technical fibers are available in a wide variety of tissues. We chose a flax warp with a weight of $478 \mathrm{~g} \cdot \mathrm{m}^{-2}$, whose properties are reported in Table 2 and provided by the Ta-Bru company. Since lamination was performed by 
Table 1. Physical and mechanical properties of some natural fibers

\begin{tabular}{ccccccc}
\hline & Diameter $[\mu \mathrm{m}]$ & Length $[\mathrm{mm}]$ & Density $[\mathrm{kg} \cdot \mathrm{m}-3]$ & S2 spiral angle $\left.{ }^{\circ}\right]$ & Tensile strength $[\mathrm{MPa}]$ & Elastic modulus [GPa] \\
\hline sisal & 20 & 1 to 8 & 1330 & 22 & 500 to 700 & 9 to 20 \\
\hline jute & 20 & 2 to 5 & 1450 & 8 & 393 to 773 & 27 \\
\hline flax & 13 to 22 & 20 to 70 & 1500 & 5 to 10 & 345 to 1100 & 28 to 100 \\
\hline
\end{tabular}

hand, reduced environmental impact resins suitable for hand lamination were selected from among the class of thermosetting polymers. Thermosetting polymers have, in fact, good mechanical strength, chemical resistance, thermal stability and durability in comparison with thermoplastic resins. The latter, in spite of their better flexibility in terms of producing even complex shapes, have to reach process temperatures higher than the degradation threshold for flax (about $230{ }^{\circ} \mathrm{C}$ ). In the set of thermosetting polymers available on the market and responding to the needs of low environmental impact, the authors have chosen two resins produced by the Polynt company. The first (Resin 181EN2X) is an isophthalic with $25 \%$ polyethylene terephthalate (PET), obtained from recycled material. The second (Resin VEef220ST) is a vinyl ester obtained from a bisphenolic epoxy resin with a low styrene content. Unlike the epoxy resins these two types of resins do not need thermal treatment after cure. In fact, thermal treatment may damage the flax fibres. The mechanical characteristics of the two resins are reported in Table 3 [21]. Considering the data reported in Table 3, it is possible to observe some differences between the isophthalic and the vinyl ester resins. In particular, the vinyl ester resin exhibits a lower elastic modulus and a higher ultimate strength than the isophthalic one. These different properties are in agreement with the related remarks in the Subsection 1.2, where it has been pointed out that a vinyl ester resin is more resilient than an isophthalic one. In order to investigate the mechanical properties of the manufactured composites, the tensile, the shear and the bending tests have been performed, following the most relevant standards [22] to [25]. The following instrumentation has been used: Instron 8033 standing press with a $25 \mathrm{kN}$ load cell, MTS 3.1 station manager software, adjustable grips for tensile testing and an ad-hoc support for three-point loading, used for both bending and shear tests, according to [24] and[25].

\section{EXPERIMENTAL}

\subsection{Specimen Preparation}

The specimens were prepared by hand, following the procedure described below: (a) spreading of a release agent on a glass plane, used as a base to facilitate the material removal at the end of the operations; (b) application of the first fabric layer, manually and uniformly wetted with the resin; (c) application of the second fabric layer, followed by manual application of the resin using a brush. The last operation was repeated until the desired thickness was reached.

After wetting the last layer, a layer of peel ply was applied on the top of the stack, in order to obtain a good surface finish.

Table 2. Fabric properties

\begin{tabular}{llc}
\hline & Units & Flax fabric 8615 \\
\hline Fiber content & {$[\%]$} & $100 \%$ flax \\
\hline Specific weight & {$\left[\mathrm{g} / \mathrm{m}^{2}\right]$} & 478 \\
\hline Yarns in warp & {$[$ threads/cm] } & 10 \\
\hline Warp count & {$[-]$} & 22 \\
\hline Yarns in weft & {$[$ threads/cm] } & 5 \\
\hline Weft count & {$[-]$} & 10 \\
\hline
\end{tabular}

Table 3. Mechanical properties of the resins

\begin{tabular}{llcc}
\hline & & 181EN2X & VEef220ST \\
\hline Tensile strength & {$[\mathrm{MPa}]$} & 60 & 65 \\
\hline Young's modulus & {$[\mathrm{MPa}]$} & 4000 & 3500 \\
\hline Elongation at break & {$[\%]$} & 2 & 2 \\
\hline Flexural strength & {$[\mathrm{MPa}]$} & 98 & 105 \\
\hline Flexural modulus & {$[\mathrm{MPa}]$} & 4100 & 3600 \\
\hline
\end{tabular}

After that, the peel ply was covered with a micro perforated film and an aerator layer. Then, the vacuum sack and the hoses for air extraction were applied. With a suitable choice of the porosity of the microperforated film, the excess resin distributed during the process was finally extracted, thus achieving the desired weight ratio between the matrix and the reinforcement. In the present experimentation, the weight was equally divided between the fibers and the resin, corresponding to a 0.5 matrixreinforcement ratio. For tensile and bending tests, specimens made up of four layers, corresponding to an overall thickness of $3.5 \mathrm{~mm} \pm 0.20 \mathrm{~mm}$ have been manufactured, whereas nine-layer, $8 \mathrm{~mm} \pm 0.20 \mathrm{~mm}$ thick specimens, were prepared for the shear tests. In order to obtain the shapes prescribed by the standards, the plates were machined at low speed without cutting 
oil [23], type 1 specimens with the dimensions shown in Fig. 3 were realized for the tensile tests. [24], method A (three-point bending) specimens with the dimensions shown in Fig. 4 were manufactured for the bending tests. In light of the difficulties encountered in manufacturing thin specimens, the specimens for the shear test were manufactured as shown in Fig. 5, following the procedure suggested by [24] for nonstandard specimens. The whole set of specimens is characterized by a principal fiber orientation parallel to the greater dimension (length). The only fibers with perpendicular orientation with respect to the aforementioned direction are those needed for laying out the warp: they are on the order of $15 \%$ of the fabric by weight.

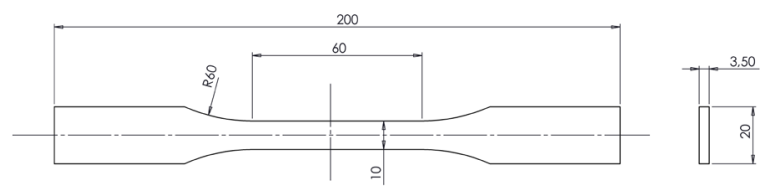

Fig. 3. Specimen for tensile test

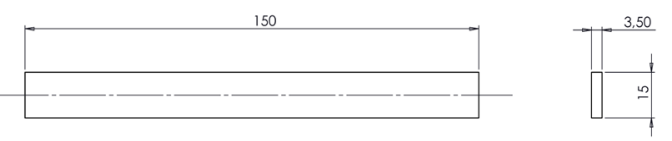

Fig. 4. Specimen for bending test

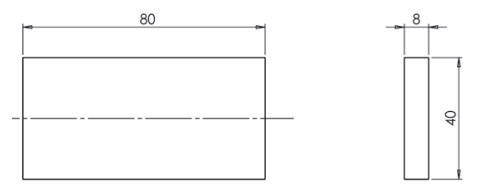

Fig. 5. Specimen for interlaminar shear strength test (short-beam method)

\subsection{Testing}

The tensile tests were performed according to [22] to [23]. Seven specimens for each resin were tested, at a room temperature $(R T)$ of $R T=23^{\circ} \mathrm{C}$, and a relative humidity $(\varphi) \varphi=50 \%$. The standing press was equipped with a $25 \mathrm{kN}$ load cell. The nominal strain was determined according to [22], method A.
The same standard was used to evaluate the Young's modulus. Since results may be significantly affected by misalignments [26], the specimens were clamped by means of self-aligning grips, with a clamping length of $115 \mathrm{~mm} \pm 1 \mathrm{~mm}$. The velocity of the crosshead was set at $1.8 \mathrm{~mm} / \mathrm{min}$ throughout the test.

The bending tests were run according to [24] standard, with a three-point bending loading configuration. The nominal span length of the specimen was $L=60 \mathrm{~mm}$. Six specimens for each resin were tested, at a room temperature of $R T=23^{\circ} \mathrm{C}$ and a relative humidity $\varphi=50 \%$. The standing press was equipped with a $25 \mathrm{kN}$ load cell. The flexural modulus $E_{f}$ was determined according to [24], method A. The crosshead velocity was set at $1 \mathrm{~mm} /$ min throughout the test. The shear tests were run according to [25] standard. Six specimens were tested at a room temperature of $R T=23^{\circ} \mathrm{C}$ and a relative humidity $\varphi=50 \%$. The standing press was equipped with a $25 \mathrm{kN}$ load cell. The crosshead velocity was set at $1 \mathrm{~mm} / \mathrm{min}$. At the end of each test, conducted under the aforementioned loading modes, the fracture surfaces were carefully examined in order to verify that the incurred failures conformed to the standard prescriptions.

\subsection{Results}

\subsubsection{Tensile Tests}

The results obtained for Resin 181EN2X and Resin VEef220ST are collected in Tables 4 and 5 and Figs. 7 and 8 respectively. Some data have been discarded (Rejected: Y) and were not considered for further analyses, as the cracking did not conform to [25] requirements.

\subsubsection{Bending Test}

Tables 6 and 7 and Figs. 9 and 10 show the bending test results for Resin 181EN2X and Resin VEef220ST, respectively.

Table 4. Tensile test results for Resin 181 EN2X

\begin{tabular}{|c|c|c|c|c|c|c|c|}
\hline Specimen ID & $\sigma_{b}[\mathrm{MPa}]$ & $E_{t}[\mathrm{MPa}]$ & Rejected & $\sigma_{b m}[\mathrm{MPa}]$ & Std. dev. [MPa] & $E_{t m}[\mathrm{MPa}]$ & Std. dev [MPa] \\
\hline 1 & 76.91 & 5076 & $\mathrm{~N}$ & \multirow{7}{*}{75.24} & \multirow{7}{*}{3.80} & \multirow{7}{*}{4860} & \multirow{7}{*}{207} \\
\hline 2 & 77.43 & 4662 & $\mathrm{~N}$ & & & & \\
\hline 3 & 79.94 & 5169 & $\mathrm{Y}$ & & & & \\
\hline 4 & 77.85 & 4898 & $\mathrm{~N}$ & & & & \\
\hline 5 & 65.18 & 4679 & $\mathrm{Y}$ & & & & \\
\hline 6 & 68.64 & 4629 & $\mathrm{~N}$ & & & & \\
\hline 7 & 75.38 & 5036 & $\mathrm{~N}$ & & & & \\
\hline
\end{tabular}


Table 5. Tensile test results for Resin VEef220ST

\begin{tabular}{|c|c|c|c|c|c|c|c|}
\hline Specimen ID & $\sigma_{b}[\mathrm{MPa}]$ & $E_{t}[\mathrm{MPa}]$ & Rejected & $\sigma_{b m}[\mathrm{MPa}]$ & Std. dev. [MPa] & $E_{t m}[\mathrm{MPa}]$ & Std. dev [MPa] \\
\hline 1 & 66.11 & 4698 & $Y$ & \multirow{7}{*}{72.27} & \multirow{7}{*}{1.03} & \multirow{7}{*}{4822} & \multirow{7}{*}{158} \\
\hline 2 & 72.14 & 4649 & $\mathrm{~N}$ & & & & \\
\hline 3 & 70.48 & 4749 & $\mathrm{~N}$ & & & & \\
\hline 4 & 73.39 & 4654 & $\mathrm{~N}$ & & & & \\
\hline 5 & 71.95 & 4988 & $\mathrm{~N}$ & & & & \\
\hline 6 & 73.01 & 4985 & $\mathrm{~N}$ & & & & \\
\hline 7 & 72.65 & 4907 & $\mathrm{~N}$ & & & & \\
\hline
\end{tabular}

Table 6. Bending test results for Resin 181 EN2X

\begin{tabular}{|c|c|c|c|c|c|c|c|c|}
\hline Specimen ID & $F_{\max }[\mathrm{N}]$ & $\sigma_{f M}[\mathrm{MPa}]$ & $E_{f}[\mathrm{MPa}]$ & Rejected & $\sigma_{f \mathrm{~mm}}[\mathrm{MPa}]$ & Std. dev. [MPa] & Efm [MPa] & Std. dev. [MPa \\
\hline 1 & 0.232 & 113.6 & 4166 & $\mathrm{~N}$ & \multirow{6}{*}{106.52} & \multirow{6}{*}{9.42} & \multirow{6}{*}{4437} & \multirow{6}{*}{414.2} \\
\hline 2 & 0.235 & 115.1 & 4659 & $\mathrm{~N}$ & & & & \\
\hline 3 & 0.201 & 98.45 & 3720 & $\mathrm{~N}$ & & & & \\
\hline 4 & 0.187 & 91.59 & 4614 & $\mathrm{~N}$ & & & & \\
\hline 5 & 0.222 & 108.7 & 4815 & $\mathrm{~N}$ & & & & \\
\hline 6 & 0.228 & 111.7 & 4653 & $\mathrm{~N}$ & & & & \\
\hline
\end{tabular}

Table 7. Bending test results for Resin VEef220ST

\begin{tabular}{|c|c|c|c|c|c|c|c|c|}
\hline Specimen ID & $F_{\max }[\mathrm{N}]$ & $\sigma_{f M}[\mathrm{MPa}]$ & $E_{f}[\mathrm{MPa}]$ & Rejected & $\sigma_{f M m}[\mathrm{MPa}]$ & Std. dev. [MPa] & Efm [MPa] & Std. dev.[MPa] \\
\hline 1 & 0.167 & 81.93 & 4368 & $\mathrm{~N}$ & \multirow{6}{*}{83.05} & \multirow{6}{*}{5.73} & \multirow{6}{*}{4513} & \multirow{6}{*}{214} \\
\hline 2 & 0.165 & 80.75 & 4503 & $\mathrm{~N}$ & & & & \\
\hline 3 & 0.169 & 82.98 & 4301 & $\mathrm{~N}$ & & & & \\
\hline 4 & 0.192 & 94.14 & 4906 & $\mathrm{~N}$ & & & & \\
\hline 5 & 0.158 & 77.52 & 4435 & $\mathrm{~N}$ & & & & \\
\hline 6 & 0.165 & 80.98 & 4570 & $\mathrm{~N}$ & & & & \\
\hline
\end{tabular}

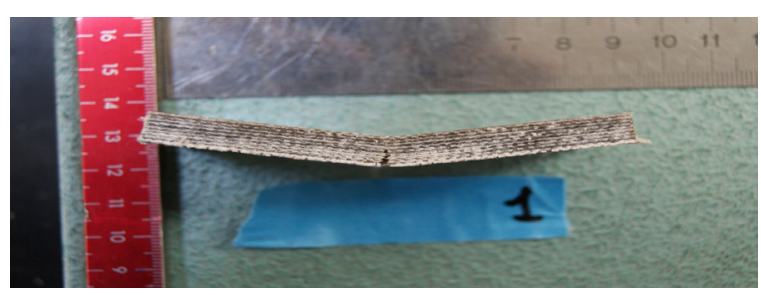

Fig. 6. Specimen fractured in shear test

\subsection{Discussion}

The data reported in Tables 4 and 5 for tensile tests and in Tables 6 and 7 for bending tests prove that the results are quite consistent with each other and repeatable. Moreover, the failure modes obtained comply with the relevant standards. Therefore, it may be concluded that both the matrix and the reinforcement contribute to the overall strength of the composite. On the other hand, results obtained in the shear test are not satisfactory due to an unacceptable failure mode of the whole set of specimens (Fig. 6). This outcome could be due to the characteristics of the laminated composite. The issue may be fixed by choosing a span length different from that suggested by the aforementioned standard, until an interlaminar failure mode is obtained. A comparison between the characteristics of the resins with and without reinforcement is reported in Table 8. The data referring to the resin without reinforcement are derived from [21] and are the same as those listed above in Table 3. In the case of resin 181 EN2X, the reinforcement increases the ultimate tensile strength UTS by about $25.4 \%$, the Young's modulus $E_{t}$ by about $21.5 \%$, the flexural strength $\sigma_{f M}$ by about $8.7 \%$ and the flexural modulus $E_{f}$ by about $8.2 \%$ with respect to the resin itself. In the case of resin VEef220ST, the beneficial effect of the reinforcement is a bit less evident in tension strength. The results are slightly controversial in the case of the flexural response, since reinforcement leads to an increase in the elastic modulus, but produces a reduction in strength. Nevertheless, the reinforcement has a significant effect on improving the strength of the composites especially in the case of resin 181 EN2X, which behaves better than resin VEef220ST. The results obtained for the first one are consistent with those retrieved in the literature, even if some authors obtained better properties for similar composites [17], [18], [27] and [28]. The data for Table 8 are compared 


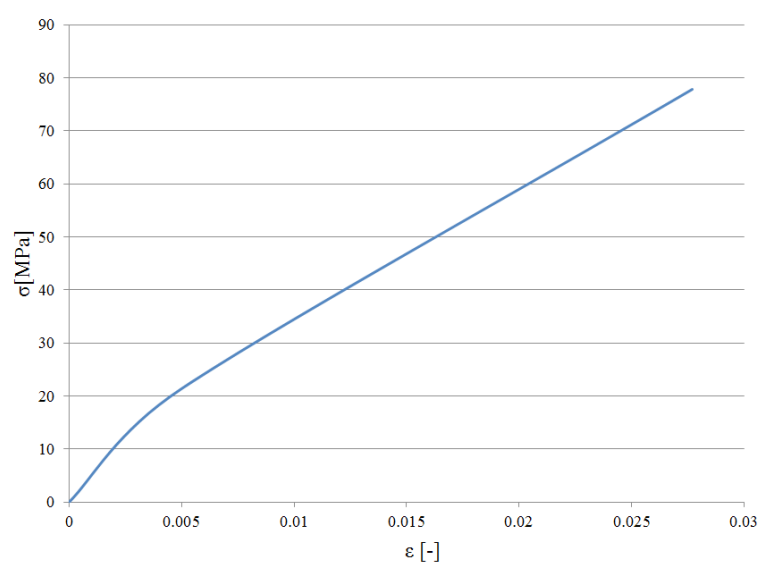

Fig. 7. Tensile test for resin 181EN2X

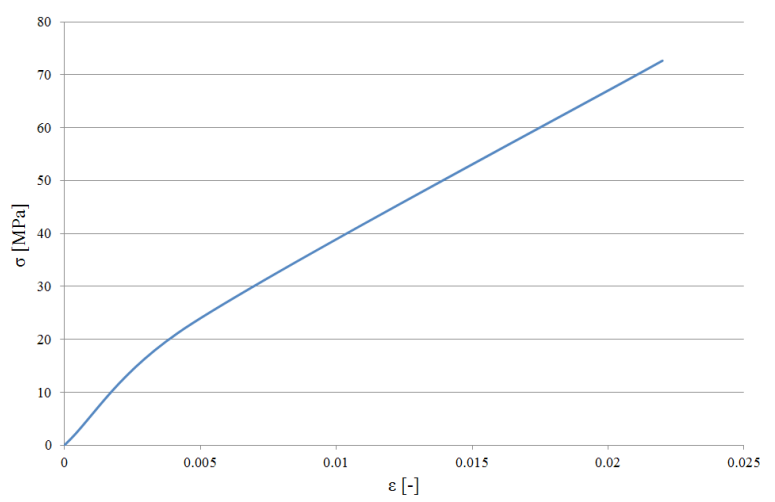

Fig. 8. Tensile test for resin VEef220ST

to each other in the histograms of Figs. 11 and 12. Confidence intervals $( \pm 2 \cdot$ Std. Dev.) are added to account for the scatter in the results reported in Tables 4 to 7 . The values of strengths and of elastic moduli for composites, having the same feature of being reinforced by flax fiber, but manufactured by conventional epoxy resins, are added in the bar graphs of Figs. 11 and 12 (data from [28]), as reference values. It can be remarked that, thanks to the enhancement provided by the reinforcement, the strength and the stiffness of the environmentally friendly composites made using flax fiber are comparable to those of the reinforced composites made using conventional resins.

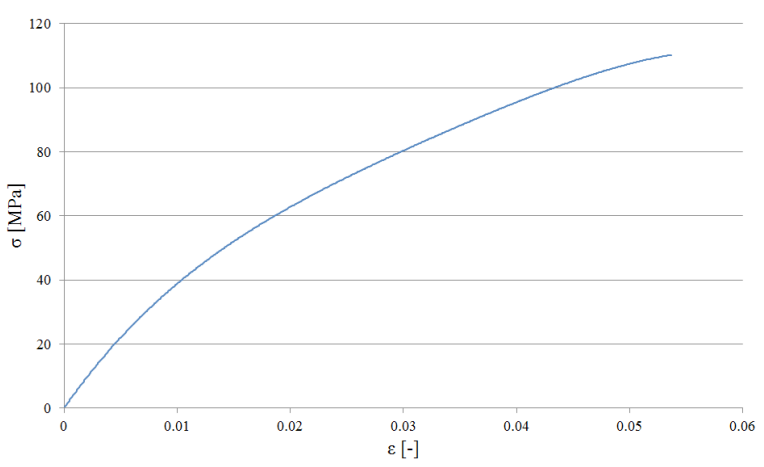

Fig. 9. Bending test for resin 181EN2X

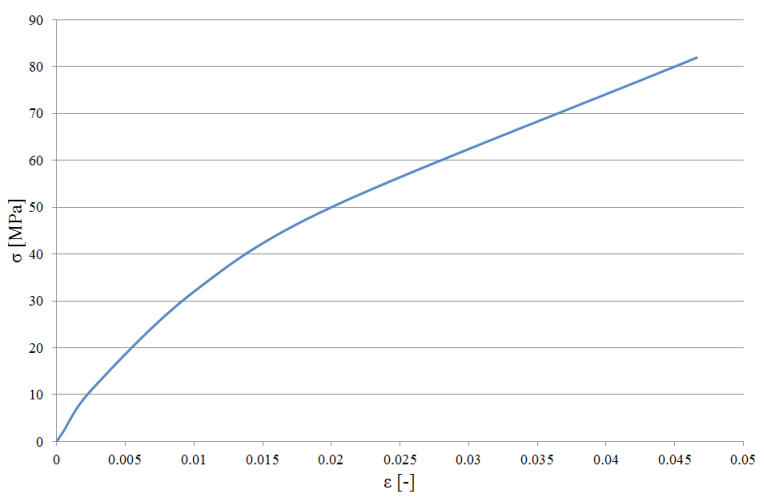

Fig. 10. Bending test for resin VEef220ST

In order to assess the matrix-reinforcement adhesion and the presence of defects, some specimens manufactured with the resin 181EN2X have been sectioned and then observed with an optical microscope. The assessment showed that the warp yarns have diameters of $500 \mu \mathrm{m}$ to $600 \mu \mathrm{m}$ (Fig. 13 ), whereas the weft yarns have diameters between $200 \mu \mathrm{m}$ and $250 \mu \mathrm{m}$ (Fig. 14). Air inclusions, shown in Fig. 15, are fewer and smaller with respect to the available data in the literature for composites manufactured for boat hulls. The analysis of the fracture surfaces of specimens tested in tension (Fig. 16) shows a homogeneous and regular surface. Such an occurrence demonstrates that both the matrix and the reinforcement participate together in the overall

Table 8. Comparison of the characteristics of the resins with and without reinforcement

\begin{tabular}{ccccccc}
\hline & $\begin{array}{c}\text { Resin 181EN2X } \\
{[\mathrm{MPa}]}\end{array}$ & $\begin{array}{c}\text { Resin 181EN2X } \\
+50 \% \text { flax [MPa] }\end{array}$ & Variation [\%] & $\begin{array}{c}\text { Resin } \\
\text { VEef220ST [MPa] }\end{array}$ & $\begin{array}{c}\text { Resin VEef220ST } \\
+50 \% \text { flax [MPa] }\end{array}$ & Variation [\%] \\
\hline UTS & 60 & 75.24 & +25.4 & 65 & 72.27 & +11.2 \\
\hline$E_{t}$ & 4000 & 4860 & +21.5 & 3500 & 4822 & +37.7 \\
\hline$\sigma_{f M}$ & 98 & 106.52 & +8.7 & 105 & 83.05 & -20.9 \\
\hline$E_{f}$ & 4100 & 4437 & +8.2 & 3600 & 4513 & +25.4 \\
\hline
\end{tabular}




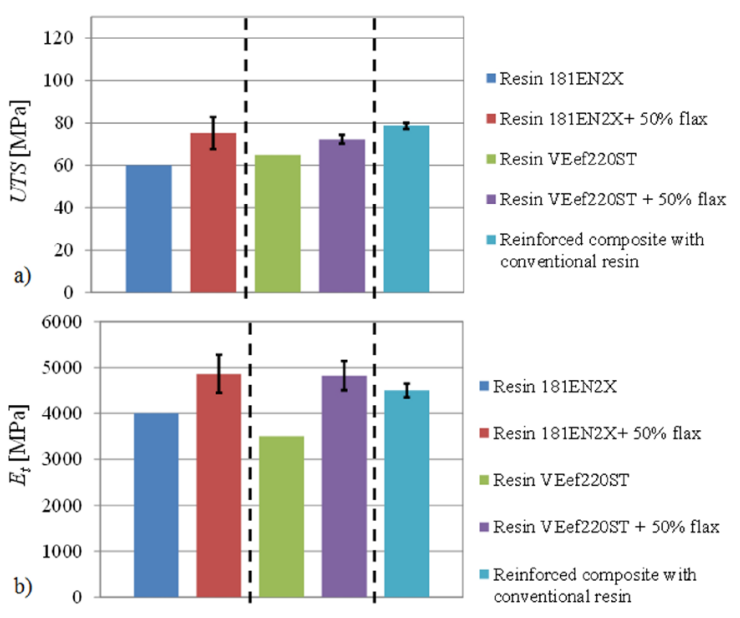

Fig. 11. Comparison between a) the ultimate strengths and b) the Young's moduli of unreinforced and reinforced composites with environmentally friendly and conventional epoxy resins [28]

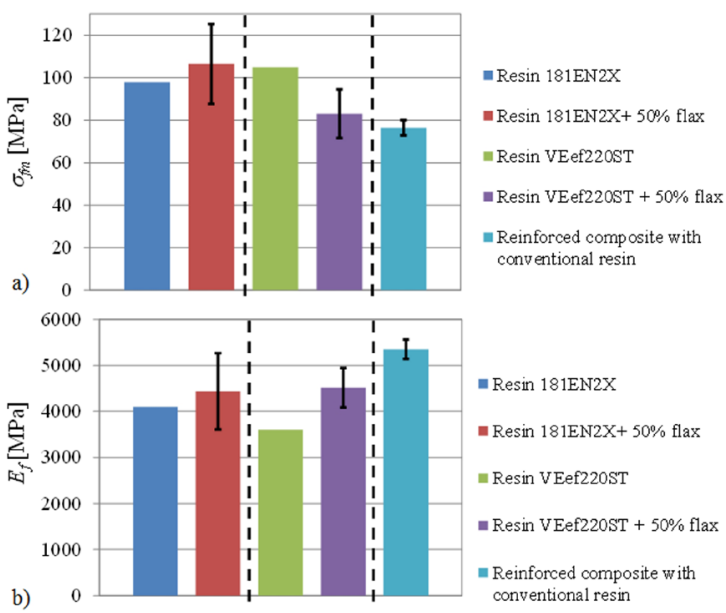

Fig. 12. Comparison between a) the flexural strengths and b) the flexural Young's moduli of unreinforced and reinforced composites with environmentally friendly and conventional epoxy resins [28]

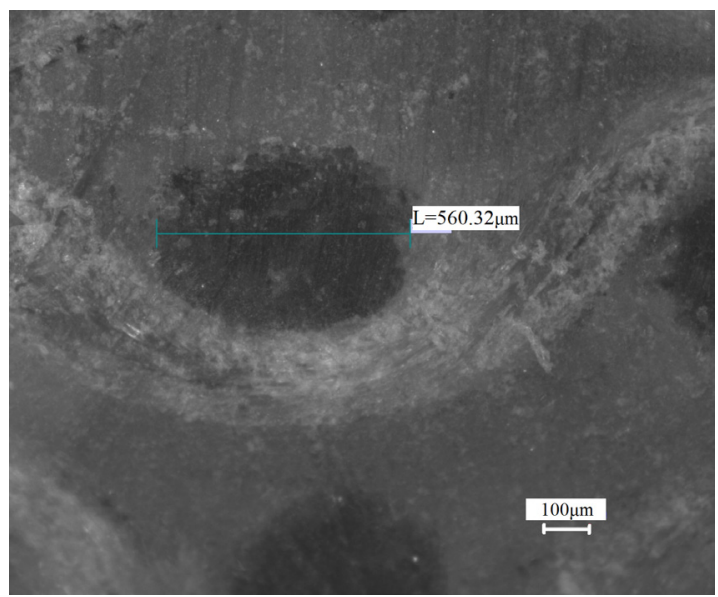

Fig. 13. Cross section of a warp yarn

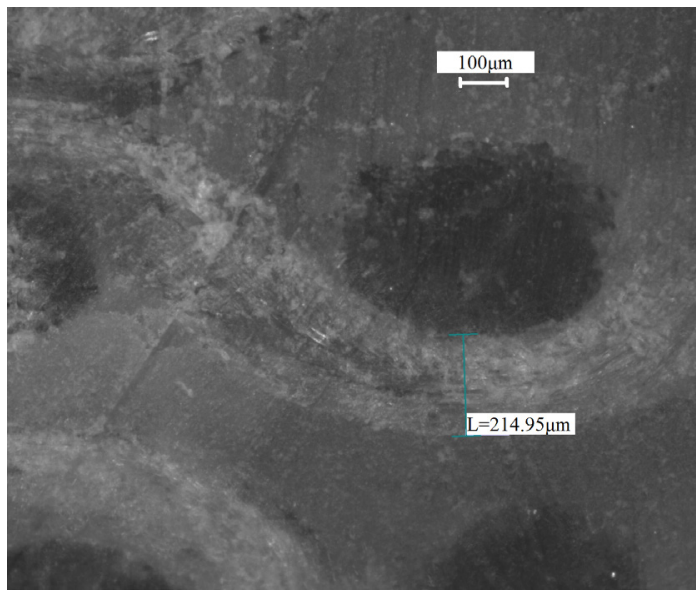

Fig. 14. Cross section of a weft yarn

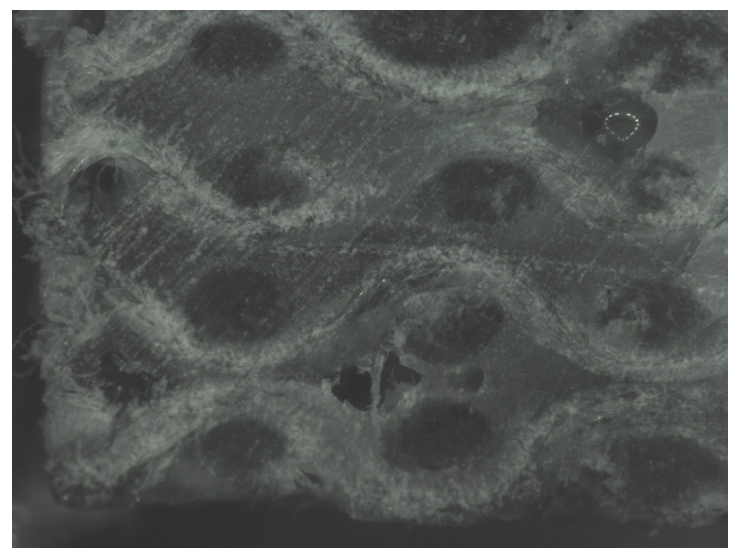

Fig 15. Air inclusion in a sectioned specimen

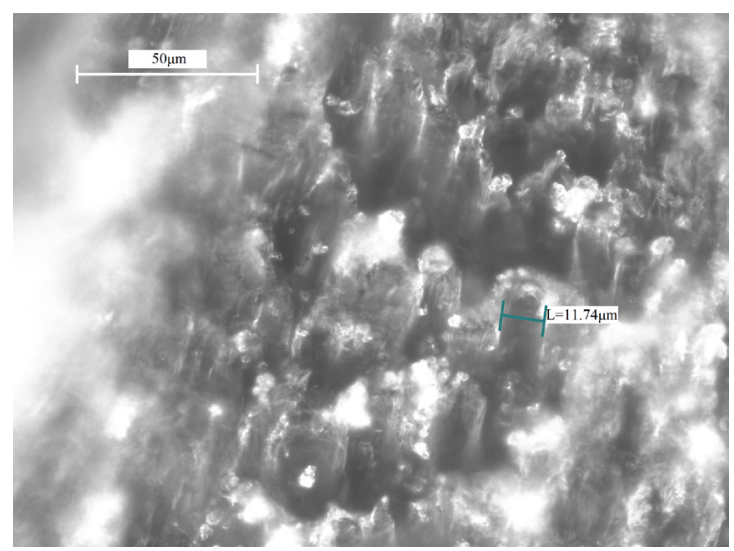

Fig. 16. Fracture surface of a specimen broken in tension

tensile strength of the composite. In other words, a good adhesion has been achieved between the two components. From the manufacturing standpoint, a drawback of the fibers used in the present study is that the fibers absorb a high amount of resin, making it 
difficult to achieve a high reinforcement to the matrix ratio.

\section{CONCLUSIONS}

The present study compares the mechanical characteristics of two different composites made of natural fiber and obtained from two different environmentally friendly resins combined with the same flax fiber reinforcement. Thirty-two specimens were manufactured by hand. They were then tested for tension, bending and shear according to the relevant international standards. The results obtained in the case of tensile and bending tests are acceptable according to the standards, whereas those coming from the shear tests have been discarded, due to unacceptable failure modes observed. Therefore, the comparison was carried out based on solely the tensile and bending test results. In light of this, the isophthalic resin (181EN2X) showed a more uniform improvement in its properties with respect to the vinylester resin (VEef220ST) in terms of strength and stiffness. In the case of the isophthalic resin, microscopic observations showed a good adhesion between the matrix and the fiber, with a small amount of air inclusions. The outcome is that the mechanical properties of the isophthalic resin are remarkably enhanced by the presence of the fiber reinforcement. In other words, this kind of resin is able to take advantage of the presence of flax fibers. Conversely, the addition of the same fibers may even have a detrimental effect with regard to the vinyl ester resin. The results of the present study show that the mechanical characteristics of composites created using environmentally friendly resins can be compared with those achievable with similar fibers but created using conventional resins.

\section{NOMENCLATURE}

$\varepsilon_{t b} \quad$ nominal strain at break [-];

$\sigma_{b} \quad$ stress at break [MPa];

$E_{t} \quad$ slope of the stress/strain curve in the strain interval between $\varepsilon_{1}=0.05 \%$ and $\varepsilon_{2}=0.25 \%$ [MPa];

$\sigma_{b m} \quad$ average value of $\sigma_{b}[\mathrm{MPa}]$

$E_{t m} \quad$ average value of $E_{t}[\mathrm{MPa}]$

$\sigma_{f M}$ flexural strength of the test specimen at maximum load [MPa];

$E_{f} \quad$ flexural modulus of elasticity [MPa];

$\sigma_{f M m} \quad$ average value of $\sigma_{f M}[\mathrm{MPa}]$

$E_{f m} \quad$ average value of $E_{f}[\mathrm{MPa}]$

$F_{\max } \quad$ failure or maximum load [N];
UTS ultimate tensile strength of the elementary fiber [MPa];

$R T \quad$ room temperature $\left[{ }^{\circ} \mathrm{C}\right]$;

$\varphi \quad$ relative humidity [-];

$L \quad$ span length [mm];

$b \quad$ specimen cross section width [mm];

$h \quad$ specimen cross section height $[\mathrm{mm}]$.

\section{REFERENCES}

[1] Hornsby, P.R., Hinrichsen, E., Tarverdi, K. (1997). Preparation and properties of polypropylene composites reinforced with wheat and flax straw fibers - Part I Fibre characterization. Journal of Materials Science, vol. 32, no. 2, p. 443-449, DOI:10.1023/A:1018521920738.

[2] Hornsby, P.R., Hinrichsen, E., Tarverdi, K. (1997). Preparation and properties of polypropylene composites reinforced with wheat and flax straw fibers - Part II Analysis of composite microstructure and mechanical properties. Journal of Materials Science, vol. 32, no. 4, vol. 1009-1015, DOI:10.1023/A:1018578322498.

[3] Croccolo, D., De Agostinis, M., Olmi, G. (2013). Experimental characterization and analytical modelling of the mechanical behaviour of fused deposition processed parts made of ABS-M30. Computational Materials Science, vol. 79, p. 506518, DOI:10.1016/J.commatsci.2013.06.041.

[4] Croccolo, D., De Agostinis, M. (2013). Analytical solution of stress and strain distributions in press fitted orthotropic cylinders. International Journal of Mechanical Sciences, vol. 71, p. 21-29, D0I:10.1016/j.ijmecsci.2013.03.002.

[5] Kopfer, H., Friedrich, C., De Agostinis, M., Croccolo, D. (2012). Friction characteristics in light weight design focusing bolted joints. Proceedings of ASME International Mechanical Engineering Congress and Exposition, Houston, vol. 3, p. 839846, D0I:10.1115/IMECE2012-85940.

[6] Troiani, E., Donati, L., Molinari, G., Di Sante, R. (2014). Influence of plying strategies and trigger type on crashworthiness properties of carbon fiber laminates cured through autoclave processing. Strojniški vestnik - Journal of Mechanical Engineering, vol. 60, no. 6, p. 375-381, DOI:10.5545/sv-jme.2013.1506.

[7] Movaghghar, A., Lvov, G.I. (2012) Theoretical and experimental study of fatigue strength of plain woven glass/ epoxy composite. Strojniški vestnik - Journal of Mechanical Engineering, vol. 58, no. 3, p. 175-182, D0l:10.5545/svjme.2011.135.

[8] Shah, D.U., Schubel, P.J., Clifford, M.J., (2013). Modelling the effect of yarn twist on the tensile strength of unidirectional plant fibre yarn composites. Journal of Composite Materials, vol. 47, no. 4, p. 425-436, DOl:10.1177/0021998312440737.

[9] Mukhopadhyay, S., Fangueiro, R. (2009). Physical modification of natural fibers and thermoplastic films for composites - A review. Journal of Thermoplastic Composite Materials, vol. 22, no. 2, p. 135-162, Dol:10.1177/0892705708091860.

[10] Faruk, O., Bledzki, A.K., Fink, H., Sain, M. (2012). Biocomposites reinforced with natural fibers: 2000-2010. 
Progress in Polymer Science, vol. 37, no. 11, p. 1552-1596, D0I:10.1016/j.progpolymsci.2012.04.003.

[11] Hughes, M. (2012). Defects in natural fibres: their origin, characteristics and implications for natural fibre-reinforced composites. Journal of Materials Science, vol. 47, no. 2, p. 599-609, D0I:10.1007/s10853-011-6025-3.

[12] Baley, C. (2002). Analysis of the flax fibres tensile behavior and analysis of the tensile stiffness increase. Composites Part A: Applied Science and Manufacturing, vol. 33, no. 7, p. 939-948, D0I:10.1016/S1359-835X(02)00040-4.

[13] Sakurada, I., Nukushina, Y., Taisuke, I. (1962). Experimental determination of the elastic modulus of crystalline regions in oriented polymers. Journal of Polymer Science, vol. 57, no. 165, p. 651-660, D0l:10.1002/pol.1962.1205716551.

[14] Booker, R.E. Sell, J. (1998). The nanostructure of the cell wall of softwoods and its functions in a living tree. Holz als Roh - und Werkstoff (European Journal of Wood and Wood Products), vol. 56, no. 1, p. 1-8, D0l:10.1007/s001070050255.

[15] Symington, M.C., Banks, W.M., West, O.D., Pethrick, R.A. (2009). Tensil testing of cellulose based natural fibres for structural composite applications. Journal of Composite Materials, vol. 43, no. 9, p. 1083-1108, DOI:10.1177/0021998308097740.

[16] Bos, H.L., Van Den Oever, M.J.A., Peters, O.C.J.J. (2002). Tensile and compressive properties of flax fibres for natural fibre reinforced composites. Journal of Materials Science, vol. 37, no. 8, p. 1683-1692, D0l:10.1023/A:1014925621252.

[17] Zhu, J., Zhu, H., Njuguna, J., Abhyankar, H. (2013). Recent development of flax fibres and their reinforced composites based on different polymeric matrices. Materials, vol. 6, no. 11, p. 5171-5198, DOl:10.3390/ma6115171.

[18] Yan, L.A., Chouw, N.A., Jayaraman, K.B. (2014). Flax fibre and its composites - A review. Composites Part B: Engineering, vol. 56, p. 296-317, D0l:10.1016/J.compositesb.2013.08.014.

[19] Oksman, K., Mathew, A.P., Långström, R., Nyström, B., Joseph, K. (2009). The influence of fibre microstructure on fibre breakage and mechanical properties of natural fibre reinforced polypropylene. Composites Science and Technology, vol. 69, no. 11-12, p. 1847-1853, D0l:10.1016/j. compscitech.2009.03.020.

[20] Ku, H., Wang, H., Pattarachaiyakoop, N. Trada, M. (2011). A review on the tensile properties of natural fiber reinforced polymer composites. Composites Part B: Engineering, vol. 42, no. 4, p. 856-873, D0l:10.1016/j.compositesb.2011.01.010.

[21] Polynt (2014), from http://www.polynt.it/ENG/homepage. aspx, accessed on 2014-06-10.

[22] ISO 2012.527-1 (2012). Plastics-Determination of tensile properties-General principles, II ed. International Organization for Standardization, Geneva.

[23] ISO 1997.527-4 (1997). Plastics-Determination of tensile properties-Test conditions for isotropic and orthotropic fobrereinforced plastic composites, I ed. International Organization for Standardization, Geneva.

[24] ISO, 1998.14125 (1998). Fibre-Renforced plastic compositesDetermination of flexural properties, I ed. International Organization for Standardization, Geneva.

[25] ISO 2003.14130 (2003). Technical corrigendum 1. FibreRenforced plastic composites-Determination of apparent interlaminar shear strength by short-beam method. International Organization for Standardization, Geneva.

[26] Olmi, G. (2011). A new loading-constraining device for mechanical testing with misalignment auto-compensation. Experimental Techniques, vol. 35 no. 6, p. 61-70, Dol:10.1111/j.1747-1567.2010.00678.x.

[27] Petrucci, R., Santulli, C., Puglia, D., Sarasini, F., Torre, L., Kenny, J. M. (2013). Mechanical characterisation of hybrid composite laminates based on basalt fibres in combination with flax, hemp and glass fibres manufactured by vacuum infusion. Materials and Design, vol. 49, p. 728-735, D0l:10.1016/j. matdes.2013.02.014.

[28] Fiore, V., Valenza, A., Di Bella, G., (2011). Mechanical behavior of carbon/flax hybrid composites for structural applications. Journal of Composite Materials, vol. 46, no. 17, p. 2089-2096, DOl:10.1177/0021998311429884. 